\title{
Uninterrupted Expression of CmSIT1 in a Sclerotial Parasite Coniothyrium minitans Leads to Reduced Growth and Enhanced Antifungal Ability
}

\author{
Xiping Sun ${ }^{1,2}$, Ying Zhao ${ }^{1,2}$, Jichun Jia ${ }^{1,2}$, Jiatao Xie ${ }^{1,2}$, Jiasen Cheng ${ }^{1,2}$, Huiquan Liu ${ }^{3}$, \\ Daohong Jiang ${ }^{1,2}$ and Yanping $\mathrm{Fu}^{2 \star}$ \\ ${ }^{1}$ State Key Laboratory of Agricultural Microbiology, Huazhong Agricultural University, Wuhan, China, ${ }^{2}$ The Provincial Key Lab \\ of Plant Pathology of Hubei Province, College of Plant Science and Technology, Huazhong Agricultural University, Wuhan, \\ China, ${ }^{3}$ State Key Laboratory of Crop Stress Biology for Arid Areas, College of Plant Protection, Northwest Agriculture and \\ Forestry University, Yangling, China
}

\section{OPEN ACCESS}

Edited by:

Hector Mora Montes, Universidad de Guanajuato, Mexico

Reviewed by:

Birinchi Kumar Sarma, Banaras Hindu University, India José Ascención Martínez-Álvarez, University of Guanajuato, Mexico

Luis Antonio Pérez-García, Universidad Autónoma de San Luis Potosí, Mexico

*Correspondence: Yanping Fu yanpingfu@mail.hzau.edu.cn

Specialty section: This article was submitted to Fungi and Their Interactions,

a section of the journal

Frontiers in Microbiology

Received: 23 July 2017 Accepted: 26 October 2017 Published: 10 November 2017

Citation: Sun X, Zhao Y, Jia J, Xie J, Cheng J, Liu H, Jiang D and Fu Y (2017) Uninterrupted Expression of CmSIT1 in a Sclerotial Parasite Coniothyrium minitans Leads to Reduced Growth and Enhanced Antifungal Ability.

Front. Microbiol. 8:2208. doi: 10.3389/fmicb.2017.02208
Coniothyrium minitans is an important mycoparasite of Sclerotinia sclerotiorum. In addition, it also produces small amounts of antifungal substances. ZS-1TN1812, an abnormal mutant, was originally screened from a T-DNA insertional library. This mutant showed abnormal growth phenotype and could significantly inhibit the growth of $S$. sclerotiorum when dual-cultured on a PDA plate. When spraying the filtrate of ZS-1TN1812 on the leaves of rapeseed, S. sclerotiorum infection was significantly inhibited, suggesting that the antifungal substances produced by this mutant were effective on rapeseed leaves. The thermo-tolerant antifungal substances could specifically suppress the growth of $S$. sclerotiorum, but could not significantly suppress the growth of another fungus, Colletotrichum higginsianum. However, C. higginsianum was more sensitive to proteinous antibiotics than S. sclerotiorum. The T-DNA insertion in ZS-1TN1812 activated the expression of CmS/T1, a gene involved in siderophore-mediated iron transport. It was also determined that mutant ZS-1TN1812 produced hypha with high iron levels. In the wild-type strain ZS-1, CmSIT1 was expressed only when in contact with $S$. sclerotiorum, and consistent overexpression of CmSIT1 showed similar phenotypes as ZS-1TN1812. Therefore, activated expression of CmSIT1 leads to the enhanced antifungal ability, and CmSIT1 is a potential gene for improving the control ability of $C$. minitans.

Keywords: Coniothyrium minitans, siderophore-mediated iron transport, antifungal substances, Sclerotinia sclerotiorum, biological control

\section{INTRODUCTION}

Coniothyrium minitans is an important mycoparasite that can parasitize and destroy both hyphae and sclerotia of fungi of the genus Sclerotinia. C. minitans can significantly reduce sclerotial inoculums and inhibit the production of apothecia (Whipps and Gerlagh, 1992; Gerlagh et al., 1999; Diamantopoulou et al., 2000; Bennett et al., 2006; Li et al., 2006; Whipps et al., 2008). C. minitans has been used to control Sclerotinia diseases of many vegetable crops (Budge and Whipps, 2001; Jones and Whipps, 2002; Jones et al., 2004; Partridge et al., 2006; McQuilken and Chalton, 2009). C. minitans has been registered as the commercial biological control agent, Contans ${ }^{\circledR} \mathrm{WG}$, which is used to reduce and control the diseases caused by S. sclerotiorum and S. minor. Recently, C. minitans 
was also developed as a biocontrol agent for stem rot of rapeseed (Brassica napus) caused by S. sclerotiorum, and a provisional registration was issued by the Chinese Ministry of Agriculture in 2015.

In addition to being a mycoparasite, $C$. minitans also produces antifungal and antibacterial substances. However, its ability to produce antifungal substances is very weak. The antifungal substances are usually not observed when dual-culturing with S. sclerotiorum on PDA medium and their production can be affected by nutrient factors (McQuilken et al., 2002; Yang et al., 2008). Recent research showed that the production of antifungal substances and mycoparasitism of C. minitans are regulated by the ambient $\mathrm{pH}$ value (Tomprefa et al., 2011). Under low $\mathrm{pH}$ conditions, C. minitans can produce more antifungal substances, but when $\mathrm{pH}$ values rise, C. minitans may produce more fungal cell wall-degrading enzymes to parasitize its hosts (Zeng et al., 2014; Lou et al., 2015). These studies suggest that $C$. minitans has the potential to produce antifungal substances, but the regulation of this production is complicated.

Fe element is an important limiting nutrient for maintaining iron homeostasis. Fungi can uptake iron via siderophores, iron permease, and non-specific divalent metal ion transporters (Van der Helm and Winkelmann, 1994; Haas et al., 2008). Fungal iron metabolism has been studied in detail in the fungal model prototype Saccharomyces cerevisiae (Kosman, 2003; Kaplan et al., 2006; Labbéet al., 2007; Winkelmann, 2007). In filamentous fungi, such as Aspergillus spp., the biosynthesis, regulation, and physiological function of siderophores have also been studied. The saprobe $A$. nidulans and the human pathogen $A$. fumigates secrete the same siderophores for iron acquisition and possess intracellular siderophores for iron storage (Eisendle et al., 2006; Seifert et al., 2008; Haas, 2014). Siderophores play a crucial role in the pathogenicity of both plant and animal pathogens (Mei et al., 1993; Heymann et al., 2002; Schrettl et al., 2004; Hissen et al., 2005; Oide et al., 2006; Haas et al., 2008; Nevitt and Thiele, 2011; Chen et al., 2013; Moore, 2013; Condon et al., 2014; Ding et al., 2014; Schwartze et al., 2014; Giuliano Garisto Donzelli et al., 2015). The iron-bound siderophores are transported into fungal cells via siderophore iron transporters (SIT), which belong to the major facilitator superfamily (MFS) (Haas et al., 2008).

Previously, we constructed a T-DNA insertional library for C. minitans. One of the mutants in this library, ZS-1TN1812, showed an abnormal growth phenotype and could significantly inhibit the growth of S. sclerotiorum when dual-cultured on a PDA plate. We further found that the T-DNA insertion likely led to the expression of a gene involved in siderophore-mediated iron transportation. In this study, the potential function of this gene was examined.

\section{MATERIALS AND METHODS}

\section{Fungal and Bacterial Strains, Plasmids, and Culture Conditions}

The wild-type strain of Coniothyrium minitans, ZS-1 (CCAM 041057), which produces pycnidia and conidia on potato dextrose agar (PDA) dishes and abundant conidia in liquid shake culture (Cheng et al., 2003), was used to construct the T-DNA insertional library. ZS-1TN1812, an abnormal mutant, was originally screened from the library. Sclerotinia sclerotiorum strain Ep-1PNA367, which was derived from the hypovirulent strain Ep-1PN by single-ascospore-isolation (Xie et al., 2006), was used to examine the antifungal ability of $C$. minitans mutants. Colletotrichum higginsianum strain Ch-1 (IMI349061) was donated by Dr Yangdou Wei (University of Saskatchewan). All strains were cultured on PDA at $20-22^{\circ} \mathrm{C}$. Agrobacterium tumefaciens strain EHA105 was used to transform the wildtype strain ZS-1 as described by Li et al. (2005) and Gong et al. (2007). Escherichia coli strain JM109 was used to construct transformation vectors (plasmids) and propagate the plasmids (Gong et al., 2007). The wild-type strain, ZS-1, its mutants, Ch-1, and S. sclerotiorum strain Ep-1PNA367 were cultured at $20^{\circ} \mathrm{C}$ on PDA or PDB, and maintained as PDA slants. A. tumefaciens and E. coli were cultured in LB medium at 28 and $37^{\circ} \mathrm{C}$, respectively, and maintained in LB containing 15-20\% glycerol at $-20^{\circ} \mathrm{C}$.

\section{Biological Characterization of ZS-1TN1812}

The growth rate, colony morphology, conidial production, and parasitic ability of ZS-1TN1812 were determined using the methods described by Qin et al. (2011). The mutant was allowed to grow on PDA plates to determine the growth rate and conidial production. To determine the colony morphology, a light microscope was used to observe the hyphal tips. Sclerotia of S. sclerotiorum were used to examine the parasitic ability of the mutant.

To determine if ZS-1TN1812 could produce antifungal substances, the mutant was dual-cultured with S. sclerotiorum strain Ep-1PNA367 on PDA. ZS-1TN1812 was activated on PDA plates, hyphal agar discs were punched out with a hole punch, and transferred on to fresh PDA plates. The inoculated plates were incubated at $20^{\circ} \mathrm{C}$ for 4 days and then hyphal agar discs were punched from the activated colonies of S. sclerotiorum strain Ep-1PNA367 and were placed at the opposite side of ZS-1TN1812-inoculated plates. The co-inoculated plates were further incubated at $20^{\circ} \mathrm{C}$ for 7 days. As a control, the wildtype strain ZS-1 was dual-cultured with Ep-1PNA367. This experiment was repeated more than five times.

The antifungal ability of mutant ZS-1TN1812 was further examined on rapeseed leaves. Mutant ZS-1TN1812 was cultured in $100 \mathrm{~mL}$ PDB in a $250 \mathrm{~mL}$ flask, shaking at $150 \mathrm{rpm}$ at $20^{\circ} \mathrm{C}$ for 12 days. The hyphae were removed by passing through three layers of filter paper and possible hyphal debris was removed by passing through a bacterial filter $(0.22 \mu \mathrm{m})$. The filtrate was collected and stored at $4^{\circ} \mathrm{C}$ before use. Rapeseed leaves were sprayed with the filtrate until fully wet. After drying out at room temperature, the leaves were inoculated with activating hyphal agar discs of $S$. sclerotiorum strain Ep-1PNA367. The inoculated leaves were then placed in a tray and maintained at $100 \%$ humidity at room temperature for 1 to 3 days. The lesion diameters induced by strain Ep-1PNA367 were measured with a ruler. The filtrate from the wild-type strain ZS-1 was used instead 
of the mutant strain ZS-1TN1812, as controls. This experiment was repeated three times.

\section{Primary Characterization of Antifungal Substances Produced by ZS-1TN1812}

To characterize the antifungal substances produced by ZS-1TN1812, filtrate was either incubated in a water bath at $60,80,100$, and $120^{\circ} \mathrm{C}$ for $30 \mathrm{~min}$ or treated with proteinase $\mathrm{K}(0.05 \mathrm{mg} / \mathrm{mL})$ at $37^{\circ} \mathrm{C}$ for $2 \mathrm{~h}$ following the method described by Jin et al. (1996). The proteinase K digestion was stopped by adding $0.5 \mu \mathrm{M}$ phenylmethanesulfonyl fluoride (PMSF). To detect the antifungal activity of the treated filtrate, $10 \%(\mathrm{v} / \mathrm{v})$ of filtrate was amended in $18 \mathrm{~mL}$ PDA in a Petri dish $(\Phi=90 \mathrm{~mm})$ and activating hyphal agar of $S$. sclerotiorum was inoculated at the center of the plate. The plates were placed at $20^{\circ} \mathrm{C}$ for 2 days. The non-treated filtrate and PDA, without any emendation, were used as controls. Furthermore, C. higginsianum was used instead of $S$. sclerotiorum to repeat this experiment, but the plates were incubated at $20^{\circ} \mathrm{C}$ for $108 \mathrm{~h}$. This experiment was repeated four times.

\section{DNA Extraction and Southern Blot Analysis}

The mycelia mass of the mutants and wild-type strain ZS-1 were harvested 4 days after growing on cellophane membrane laid on PDA (CM-PDA, pH 6.2-6.5) plates, and were used for genomic DNA extraction. Genomic DNA extraction was performed with the CTAB method (Sambrook and Russell, 2001). For Southern blot analysis of the T-DNA insertion in ZS-1TN1812 and copy number determination of CmSIT1 in C. minitans, the protocols were performed according to Gong et al. (2007) with minor modifications. HPH and CmSIT1 fragment were used as probes amplified with primer pairs HPH-SP/HPH-AP and N1812LBFP1(EX)/ N1812LBFP2(EX) respectively.

\section{Cloning and Sequence Analysis of the Gene with the T-DNA Insertion}

The sequences flanking the insertional T-DNA were acquired using the inverse polymerase chain reaction (iPCR) technique following the methods described by Meng et al. (2007). Genomic DNA of ZS-1TN1812 was extracted. The primer pairs LB1/Pttrpc01 and LB3/Pttrpc01 are listed in Table 1. The PCR product was ligated to the TA cloning vector, pMD18-T, and then transformed into E. coli JM109 cells. The positive clones were sequenced at Beijing Sunbiotech Co., Ltd, and sequences were analyzed with DNAMAN version 5.2.9 software (Lynnon Biosoft). The DNA sequence was used to design additional specific primers N1812SalIL1/N1812LB1, N1812SalIL2/N1812LB2, N1812HindIIIR1/N1812RB1, and N1812HindIIIR2 /N1812RB2 (see Table 1) for inverse PCR amplification to obtain additional flanking genomic DNA. The DNA sequences obtained were used to search a local C. minitans genome database with the BLASTn program and then the T-DNA insertion in ZS-1NT1812 was localized and confirmed. Based on the BLASTn result, the T-DNA was inserted at the promoter region of a gene named CmSIT1. The full-length cDNA of CmSIT1 was obtained by RT-PCR amplification.
TABLE 1 | The primers used of PCR.

\begin{tabular}{|c|c|c|}
\hline Primers & Sequence $\left(5^{\prime}-3^{\prime}\right)$ & Usage \\
\hline Pttrpc01 & ATGTCCTCGTTCCTGTCTGCTAATA & \multirow{2}{*}{$\begin{array}{l}\text { First PCR reaction for } \\
\text { T-DNA left border }\end{array}$} \\
\hline LB-1 & AGGGTTCCTATAGGGTTTCGCTCAG & \\
\hline Pttrpc01 & ATGTCCTCGTTCCTGTCTGCTAATA & \multirow{2}{*}{$\begin{array}{l}\text { Second PCR reaction } \\
\text { for T-DNA left border }\end{array}$} \\
\hline LB-3 & GAATTAATTCGGCGTTAATTCAGT & \\
\hline N1812Sall L1 & AGTCGCCAACAACAGGAT & \multirow{2}{*}{$\begin{array}{l}\text { First PCR reaction for } \\
\text { gene left border }\end{array}$} \\
\hline N1812 LB1 & CCATCATTTGGGCTGTAAG & \\
\hline N1812Sall L2 & AGTCGCCAACAACAGGAT & \multirow{2}{*}{$\begin{array}{l}\text { Second PCR reaction } \\
\text { for gene left border }\end{array}$} \\
\hline N1812 LB2 & ACTGAGGGTTGTCGTGTTC & \\
\hline N1812HindIIIR1 & GCTTGTAAACCTGGACCCT & \multirow{2}{*}{$\begin{array}{l}\text { First PCR reaction for } \\
\text { gene right border }\end{array}$} \\
\hline N1812RB1 & GAAGTGGAGTAAACGACCTG & \\
\hline N1812HindllIR2 & GCTTGTAAACCTGGACCCT & \multirow{2}{*}{$\begin{array}{l}\text { Second PCR reaction } \\
\text { for gene right border }\end{array}$} \\
\hline N1812RB2 & CTTAGGCAAGCCCACAT & \\
\hline $\mathrm{HPH}-\mathrm{SP}$ & TTCTGCGGGCGATTTGTG & \multirow{2}{*}{$\begin{array}{l}\text { The probe for T-DNA } \\
\text { copy number }\end{array}$} \\
\hline $\mathrm{HPH}-\mathrm{AP}$ & AGCGTCTCCGACCTGATG & \\
\hline N1812LBFP1(EX) & TAAGTAGAACACGACAACCCTC & \multirow{2}{*}{$\begin{array}{l}\text { The probe for CmSIT1 } \\
\text { gene copy number }\end{array}$} \\
\hline N1812LBFP2(EX) & TGCCTAAAGTAACGCAGATT & \\
\hline SIT1SP(EX) & ССАCTTCCAACCCGACAC & \multirow{2}{*}{$\begin{array}{l}\text { CmSIT1 primers for RT- } \\
\text { PCR }\end{array}$} \\
\hline SIT1AP(EX) & CTTACGCCTCCGACAAAT & \\
\hline PEX14-3'RACE2 & CGCCCTCGGTGAAATGGA & \multirow{2}{*}{$\begin{array}{l}\text { CmPEX14 primers for } \\
\text { RT- PCR }\end{array}$} \\
\hline$P-A P(E X)$ & AAGAGCCTTGGGAATGAGAT & \\
\hline Actin-FP & ACCGTGAGAAGATGACCC & \multirow{2}{*}{$\begin{array}{l}\text { Actin primers for RT- } \\
\text { PCR }\end{array}$} \\
\hline Actin-RP & AAGGACAGAAGGCTGGAAG & \\
\hline qRT-PCR-FP1 & TCCTGTTGTTGGCGACTC & \multirow{2}{*}{$\begin{array}{l}\text { CmSIT1 primers for } \\
\text { qRT-PCR }\end{array}$} \\
\hline qRT-PCR-RP1 & CGGCAGCGACAAGAGTAG & \\
\hline CmACT289 & GTCCGTGACATCAAGGAGAAGC & \multirow{2}{*}{$\begin{array}{l}\text { Actin primers for } \\
\text { qRT-PCR }\end{array}$} \\
\hline CmACT419 & ПT GCCAATGGTGATGACCTGAC & \\
\hline
\end{tabular}

SIT1-SP(OVER-T) GGATCCCAATGACGGACACCGAAA CMSIT1 CDNA

SIT1-AP(OVER-T) ATCGATGCTTGTAAACCTGGACCCT

To investigate the possible functions of CmSIT1, the full length of the putative protein was used to search the GenBank database using the BLAST program of the NCBI website. Multiple alignments of CmSIT1 amino acids were conducted using the Clustal $\mathrm{X}$ version 2.0 program (Larkin et al., 2007). The 3D structure of CmSIT1 was predicted using the Phyre2 server (Kelley and Sternberg, 2009; Kelley et al., 2015) and RaptorX web server (Källberg et al., 2012).

\section{RT-PCR for Detecting CmSIT1 and CmPEX14 Expression Pattern}

To understand the expression pattern of CmSIT1, the total RNA was extracted from the mycelial mass, which was harvested after 
incubating on PDA for 48, 72, 96, or $120 \mathrm{~h}$. The extraction of total RNA was conducted using TRIzol ${ }^{\circledR} 130$ Plus RNA Purification Kit (Invitrogen, USA) and potential DNA contamination was removed by RNase-free DNase I treatment (TaKaRa, Dalian, China), according to the manufacturer's instructions. Firststrand cDNA was synthesized using RevertAid ${ }^{\mathrm{TM}}$ First Strand cDNA Synthesis Kit (MBI, Fermentas, USA), following the manufacturer's instructions. Total cDNA abundance in the samples was normalized using the actin gene as a control, which was amplified by primer pairs Actin-FP/Actin-RP. Primers pairs SIT1SP (EX)/ SIT1AP (EX) and PEX14-3'RACE2/P-AP (EX) for RT-PCR amplification (Table 1).

\section{Construction of CmSIT1 Overexpression Vectors and ZS-1 Transformation}

Since the expression of CmSIT1 in the wild-type strain ZS-1 was undetectable with RT-PCR when growing on PDA and the TDNA insertion led to high expression of CmSIT1, we suspected that the abnormal phenotype of ZS-1TN1812 was due to the overexpression of CmSIT1. Therefore, an overexpression vector pOESIT1 was constructed and transformed into the wild-type strain ZS-1 using the Agrobacterium-mediated transformation system as described by Li et al. (2005). Primer SIT1-SP (OVERT)/SIT1-AP(OVER-T) were used to obtain the full length cDNA of CmSIT1.

\section{Determination of $\mathrm{CmSIT1}$ Expression in C. minitans in Contact with Host Fungus and Non-host Fungus}

To determine whether CmSIT1 could be expressed when C. minitans is contacting its host or non-host fungi, strain ZS-1 of C. minitans, strain Ep-1PNA367 of S. sclerotiorum, and strain Ch-1 of C. higginsianum were grown on CM-PDA plates for 3 days. The mycelial mass (about $0.25 \mathrm{~g}$ ) of C. minitans was obtained and mixed with either an equal mycelial mass of strain Ep-1PNA367 or strain Ch-1 in a sterilized mortar. The mixed mycelial mass was amended with $1 \mu \mathrm{L} \mathrm{ddH}_{2} \mathrm{O}$, and then ground finely with a pestle. About $200 \mu \mathrm{L}$ homogenate was sampled and spread on CM-PDA plates and allowed to grow at $20^{\circ} \mathrm{C}$ for 2,4 , or 5 days. The mycelial mass of the culture mixture was sampled to extract RNA for determining the transcripts of CmSIT1 with quantitative real time PCR (qRT-PCR). The first strand cDNA was reverse-transcribed with the kit described above and used for quantitative PCR (qPCR) analysis with the CFX96 Real-Time PCR Detection System (Bio-Rad, USA). The reaction volume was $20 \mu \mathrm{L}$ and each sample had three replicates. The program was as follows: denaturation at $95^{\circ} \mathrm{C}$ for $1 \mathrm{~min}$, followed by 49 amplification cycles of $95^{\circ} \mathrm{C}$ for $10 \mathrm{~s}$ and $58^{\circ} \mathrm{C}$ for $30 \mathrm{~s}$. The melt curve was generated to verify the specificity of the amplification (from 65 to $95^{\circ} \mathrm{C}$ with an increment of $0.5^{\circ} \mathrm{C}$ per cycle, with each cycle held for $5 \mathrm{~s}$ ). The mycelial mass of strain ZS-1 was ground and spread on cellophane membrane laid on PDA and grown 2, 4 , or 5 days and then harvested for RNA extraction and qRTPCR analysis as controls, and the expression of $C$. minitans actin was used as a reference gene. The primer sequences QPCR-FP1/
QPCR-RP1 and CmACT289/CmACT419 were listed in Table 1. This experiment was performed four times.

\section{Iron Stress Assay}

To test the fungal strain for iron stress tolerance, different concentrations of ferric chloride $(1,1.5,2$, or $2.5 \mathrm{mM})$ were added in $20 \mathrm{~mL}$ PDA in $90 \mathrm{~mm}$ Petri dishes. An activating hyphal agar plug of C. minitans was inoculated at the center of each plate. The plates were cultured at $20^{\circ} \mathrm{C}$ in an incubator for 12 days. The PDA plates, without any emendation, were used as controls. After 12 days, photographs of colonies were taken and colony diameters were measured. This experiment was repeated four times.

\section{Iron Level Determination in C. minitans}

To determine the possible accumulation of iron in mutant and wild-type colonies of C. minitans, iron concentrations in hyphal masses were measured. Both the mutant ZS-1TN1812 and the wild-type strain ZS-1 were grown on CM-PDA plates for 2 days, and then the mycelial mass was harvested for iron determination. For each sample, the $100 \mathrm{mg}$ mycelial mass was finely ground under liquid nitrogen with a mortar and pestle. The hyphal powder was transferred to a clean $5 \mathrm{~mL}$-tube with $2 \mathrm{~mL}$ ice-cold PBS buffer. The mixture was further subjected to sonication with an ultrasonic cleaner (SB5200DT, Wuhan, China) for $20 \mathrm{~min}$, on ice-water. Then, the liquid in the $5 \mathrm{~mL}$ tube was centrifuged at $12,000 \mathrm{rpm}$ for $10 \mathrm{~min}$ at $4^{\circ} \mathrm{C}$. The clear supernatant was transferred into a clean $2 \mathrm{~mL}$-tube. The supernatant samples were either stored at $-80^{\circ} \mathrm{C}$ or subjected to iron concentration determination. The Quantichrom ${ }^{\mathrm{TM}}$ Iron Assay Kit (Bioassay Systems, USA) was used to determine the iron concentration, following the manufacturer's instructions. The iron concentration was measured at a wavelength of $590 \mathrm{~nm}$ with an automatic micro plate reader (BOX 998, BioTek ${ }^{\circledR}$ Instruments, Inc. USA). PBS was used instead of a sample as the blank control. This experiment was performed 3 times.

\section{Data Analyses}

SAS version 8.1 (SAS Institute, Inc., Cary, NC, USA) was used to analyze the variation between treatments for each experiment using an ANOVA. When significant treatment effects were found, means of different treatments were compared using the protected least significant difference test at $P=0.05$.

\section{RESULTS}

\section{ZS-1TN1812 Has Abnormal Phenotypes}

ZS-1TN1812 grew slowly in sectors on PDA plates, with the growth rate being about $1.4 \mathrm{~mm} / \mathrm{d}$, while the wild-type strain, ZS1 , was about $3.0 \mathrm{~mm} / \mathrm{d}$. The hyphal tips of mutant ZS-1TN1812 branched excessively, and the hyphae in the colony centers were frequently vacuolated. The mutant, ZS-1TN1812, may have produced a few pycnidia, but no conidia were formed in the pycnidia, while $1.3 \times 10^{9}$ conidia were produced in each $9 \mathrm{~cm}$ Petri dish by strain ZS-1 14 days post-incubation. The colony of the mutant strain developed on PDA, with a yellow to brown appearance, while the typical colony of the wild-type strain, ZS-1 was filled with dark pycnidia (Figure 1). Furthermore, 
mutant ZS-1TN1812 could not parasitize and cause the decay of S. sclerotiorum sclerotia after 30 days, while strain ZS-1 decayed the sclerotia completely.

\section{ZS-1TN1812 Could Produce Many Antifungal Substances}

C. minitans is able to produce antifungal substances (AFS) under low $\mathrm{pH}$ conditions, but this ability is weakened when growing on PDA medium (McQuilken et al., 2002; Yang et al., 2008). However, ZS-1TN1812 could produce a large amount of antifungal substances. When dual-cultured with strain Ep-1PNA367 on PDA, ZS-1TN1812 inhibited the growth of S. sclerotiorum, the two colonies did not intermingle with each other, and the inhibition zone was maintained indefinitely. While the wild-type strain ZS-1 colonies intermingled with the colonies of S. sclerotiorum, no inhibition zone could be observed.

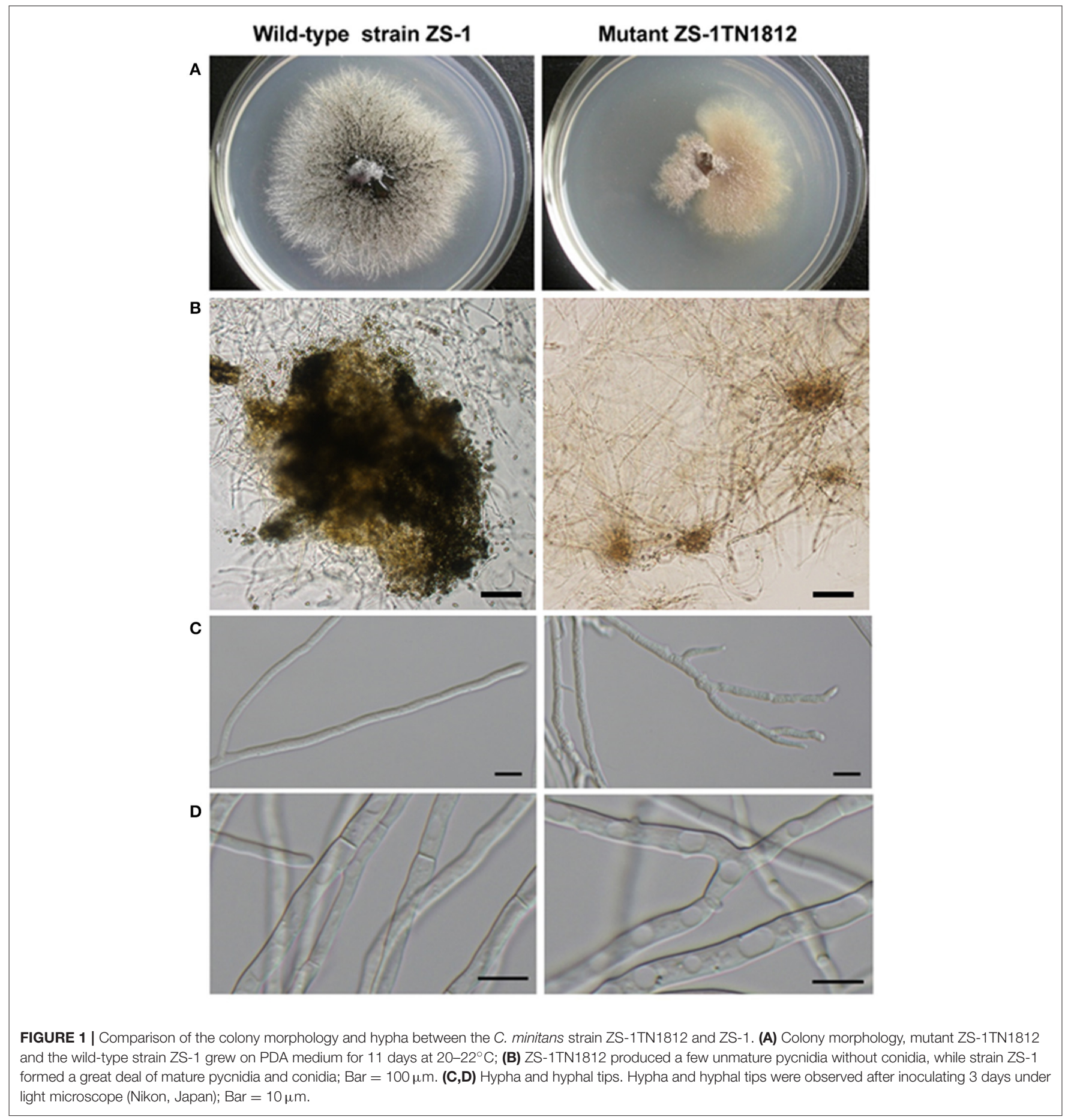


Similar inhibition was observed when dual-culturing on low-pH MCD medium (data not shown). Furthermore, the filtrate of ZS-1TN1812 could suppress the infection of S. sclerotiorum on rapeseed leaves, while the filtrate of the wild-type strain ZS-1 could only slightly delay the infection of S. sclerotiorum (Figure 2).

C. minitans' AFS may contain different components. We detected the antagonistic ability of AFS against $S$. sclerotiorum (host) and C. higginsianum (non-host). When $2 \mathrm{~mL}$ filtrate of ZS-1TN1812 was amended into $18 \mathrm{~mL}$ PDA medium, the filtrate almost fully inhibited the hyphal growth of S. sclerotiorum and C. higginsianum. However, when the filtrate was treated with high temperature or proteinase $\mathrm{K}$, the antagonistic ability of the filtrate to $S$. sclerotiorum and C. higginsianum was significantly different. The antagonistic ability of $100^{\circ} \mathrm{C}$-treated filtrate to S. sclerotiorum was not significantly different from non-treated filtrate, but the antagonistic ability was fully lost when the filtrate was treated with $120^{\circ} \mathrm{C}$ heat. The antagonistic ability was also maintained when the filtrate was treated with proteinase $\mathrm{K}$. These data suggested that the antifungal component against S. sclerotiorum is not likely to be a protein.

Interestingly, although the non-treated filtrate produced by ZS-1TN1812 could inhibit the growth of C. higginsianum, the filtrate completely lost the activity when bathed at $60^{\circ} \mathrm{C}$ or treated with proteinase $\mathrm{K}$ (Figure 3). The phenomenon suggested that the antifungal component against $C$. higginsianum is very likely to be a proteinous substance. Thus, the antifungal substances produced by ZS-1TN1812 may contain both a proteinous component and a non-proteinous component, with S. sclerotiorum being sensitive to the non-proteinous substances, while C. higginsianum is sensitive to the proteinous substance.

\section{T-DNA Insertion Activated the Expression of CmSIT1 in ZS-1TN1812}

Southern blot analysis showed only one T-DNA insertion in ZS-1TN1812 (Figure 4A). A DNA segment of $\sim 1,800$ bp was successfully amplified with inverse PCR from the region flanking the left side of T-DNA, after the genomic DNA of ZS-1TN1812 was digested with Kpn I (Figure 4B). The DNA fragment obtained was sequenced and used to search a local C. minitans ZS-1 genome database. The right flank of the inserted T-DNA was confirmed with PCR amplification (Figure 4C). We found that there were two putative genes flanking the T-DNA insertion. These two genes were arranged in the opposite direction and the un-translation space between the two genes was $997 \mathrm{bp}$ (Figure 4E). Flanking the right side of the T-DNA insertion was a putative gene encoding a protein that is a homolog of peroxisomal membrane anchor protein 14 (PEX14), and flanking the left side was a putative gene encoding a protein that is a homolog of the siderochrome iron transporter (SIT). The two putative genes were named CmPEX14 and CmSIT1, respectively.

To probe if these two genes were expressed in the wildtype and mutant strains, the total RNA was extracted from
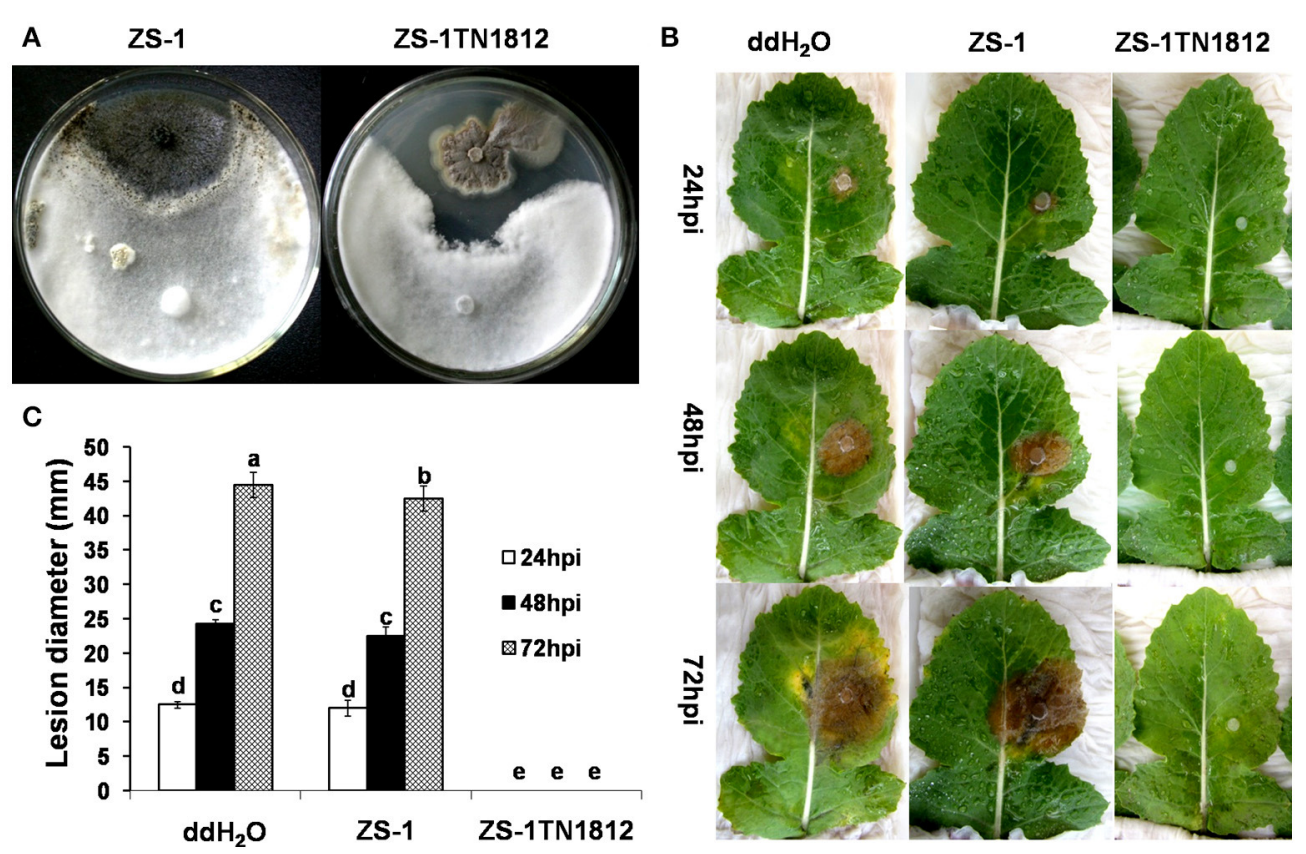

FIGURE 2 | C. minitans mutant ZS-1TN1812 strongly inhibited the growth and infection of S. sclerotiorum both on PDA and on rapeseed leaves. (A) ZS-1TN1812 dual-cultured with S. sclerotiorum, showing an inhibition zone. The wild-type strain ZS-1 was used as a control. Co-inoculated plates were placed at $20^{\circ} \mathrm{C}$ for 7 days. $\mathbf{( B , C )}$ The filtrate of ZS-1TN1812 fully suppressed the infection of S. sclerotiorum on rapeseed leaves. The hyphae were removed by passing through three layers of filter paper and possible hyphal debris was removed by passing through a bacterial filter $(0.22 \mu \mathrm{m})$. Rapeseed leaves were sprayed with the filtrate until fully wet. Bars indicate standard error. Error bars indicate the SD from three replicate means. Means followed by the different letters on the top of each column are significantly different at the $P<0.05$ level of confidence according to Duncan's multiple range test. 
A
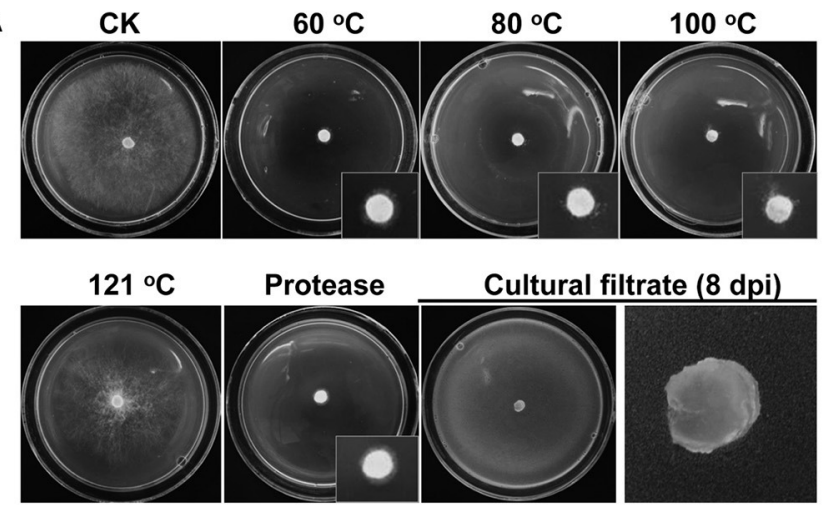

C

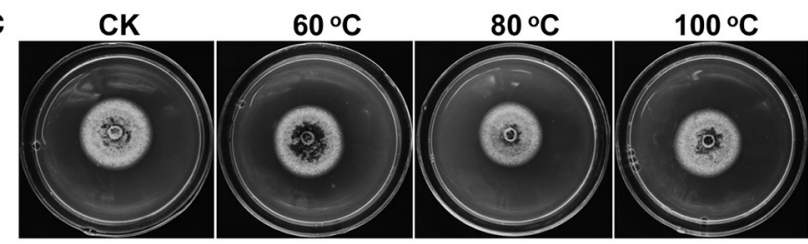

$121^{\circ} \mathrm{C}$

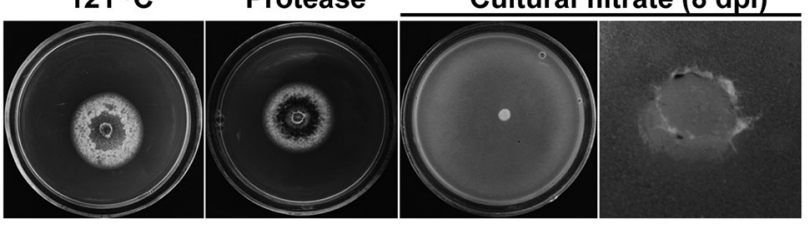

B

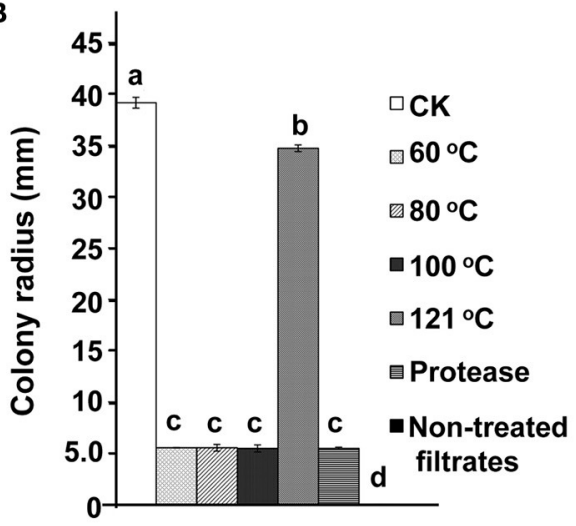

D

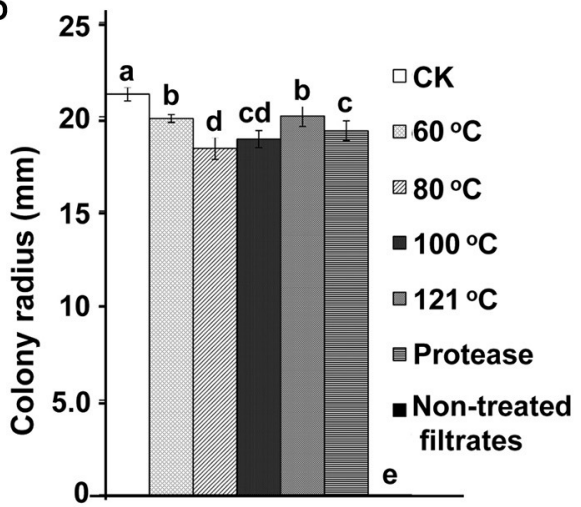

FIGURE 3 | Two kinds of antifungal substances produced by the C. minitans mutant ZS-1TN1812. (A,B) Antifungal substances that inhibit S. sclerotiorum were thermo-tolerant and protease-tolerant, suggesting the antifungal substances were not proteinous substances. (C,D) Antifungal substances that inhibit C. higginsianum were thermo-sensitive and protease-sensitive, suggesting that the antifungal substances to $C$. higginsianum were proteinous substances. Non-treated filtrates of ZS-1TN1812 fully suppressed the hyphal growth of both S. sclerotiorum and C. higginsianum. Bars indicate standard error. Means followed by the different letters on the top of each column are significantly different at the $P<0.05$ level of confidence according to Duncan's multiple range test.

the mycelial mass collected from colonies growing for 2 to 5 days on PDA plates and RNA samples were examined with RT-PCR amplification. The results showed that CmPEX14 was constitutively expressed in both the wild-type strain and in ZS-1TN1812, suggesting that the T-DNA insertion in the mutant did not significantly destroy CmPEX14 (Figure 4F). Surprisingly, the expression of CmSIT1 in the wild-type strain was not detected from these RNA samples, but was constitutively detected in ZS-1TN1812 (Figure 4F). Thus, the CmSIT1 was activated by insertion of T-DNA, and we supposed that the abnormal phenotype of mutant was possibly due to the overexpression of CmSIT1.

\section{CmSIT1 Encodes a Putative Siderochrome-Iron Transporter}

The full length CmSIT1 is 2,510 bp, with seven exons and the full length of cDNA is $2,052 \mathrm{bp}$, coding for a putative protein with 683 amino acid residues (GenBank Acc. No. MF447899). Southern blot analysis showed only one copy of CmSIT1 in the genome of $C$. minitans (Figure 4D). This putative protein may have 13 transmembrane domains, as predicted with TMHMM Server v. 2.0 (http://www.cbs.dtu.dk/services/TMHMM/). Blastp analysis using the NCBI database showed that CmSIT1 had a conserved domain (amino acid 124-amino acid 490) of the MFS transporter (cd06174) (Figure 5A). This conserved domain was also identified with the Phyre2 and RaptorX programs, showing that the heterogens in the predicted binding site contained metal ions and most are iron ions. A structural model of CmSIT1 was constructed with the E. coli multidrug transporter MdfA1pw4:A (Heng et al., 2015) as a template and the iron-binding site was displayed (Figure 5B). Thus, CmSIT1 is most likely a MFS transporter for iron uptake.

Siderophore-mediated $\mathrm{Fe}^{3+}$ uptake in fungi is accomplished through SIT transporters, a subfamily of the major facilitator superfamily. Blastp analysis showed that CmSIT1 has homologs with other fungi and it was highly homologous to the MFS transporter of Penicillium expansum (KGO39626.1), with $31 \%(183 / 585)$ identity, 54\% similarity (319/585), and a $2 \%(17 / 585)$ gap. CmSIT1 also has considerable identity $(25 \%, 141 / 569)$ and similarity $(48 \%, 274 / 569)$ to the SIT1 protein of the S. cerevisiae strain S288c (NP_010849.3). The identity and similarity of CmSIT1 and other selected proteins were listed in Table 2. A phylogenetic tree analysis was constructed based on reference proteins from A. fumigatus, 


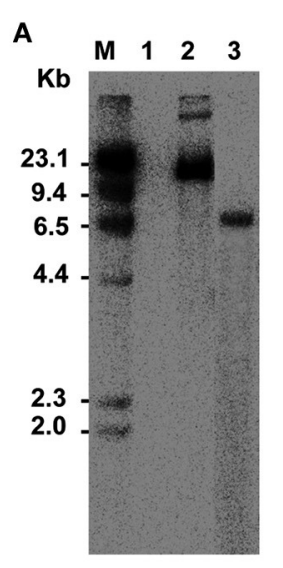

E

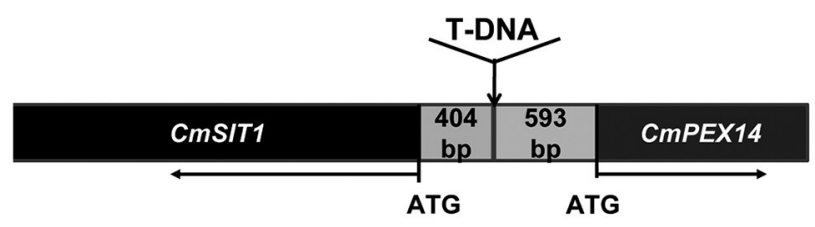

C

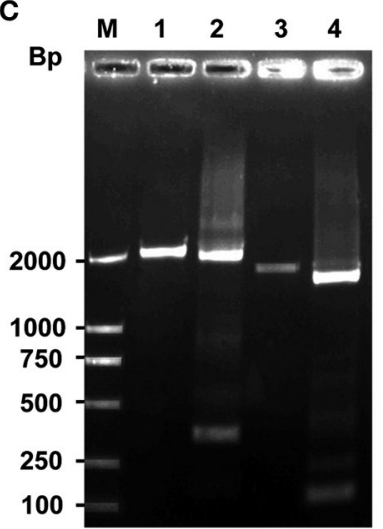

D

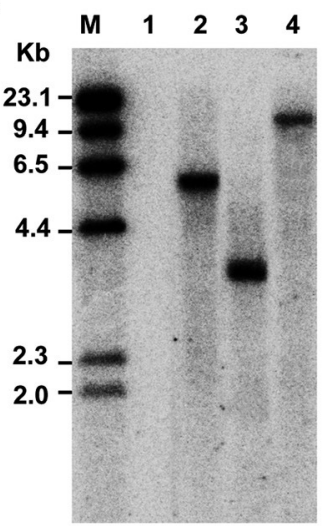

F
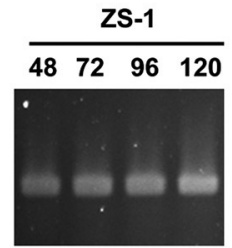

ZS-1TN1812
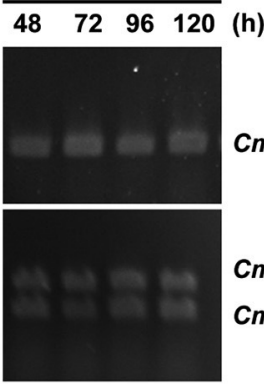

CMPEX14

CmSIT1

CmActin

FIGURE 4 | T-DNA insertion and the disrupted gene in C. minitans mutant ZS-1TN1812. (A) Southern blot analysis of the copy number of T-DNA; the genomic DNA of ZS-1TN1812 and the wild-type strain ZS-1 were digested with Sacl. Lane M, DNA weight marker, $\lambda$ DNA digested with Hind?; Lane 1, ZS-1; Lane 2, Plasmid DNA used for transformation; Lane 3, the mutant ZS-1TN1812. Hygromycin resistance gene (HPH) labeled with $\alpha^{-}{ }^{32} \mathrm{P}$ was used as the probe. (B) Amplification of the region flanking the left side of T-DNA in ZS-1TN1812 using IPCR; Lane 1 and lane 2 were the PCR products of the first round and the second round amplification. (C) The full length CmSIT1 DNA sequences obtained by utilizing iPCR; Lane 1-2, iPCR products of the left border genome DNA; Lane 3-4, iPCR products of the region flanking the right side of T-DNA; (D) CmSIT1 has only one copy in the genome of C. minitans as determined with Southern blot analysis. Lane M, DNA weight marker, $\lambda$ DNA digested with Hind?; Lane 1, Mock; Lane 2-4, genomic DNA digested by EcoRI, Pstl, and Xbal. (E) Diagram of T-DNA insertion site, T-DNA was inserted at the non-transcription region between two putative genes, CmSIT1 and CmPEX14. (F) RT-PCR analysis of the expression pattern of putative CmSIT1 and CMPEX14 in the wild-type strain ZS-1 and mutant ZS-1TN1812 cultured on PDA medium.
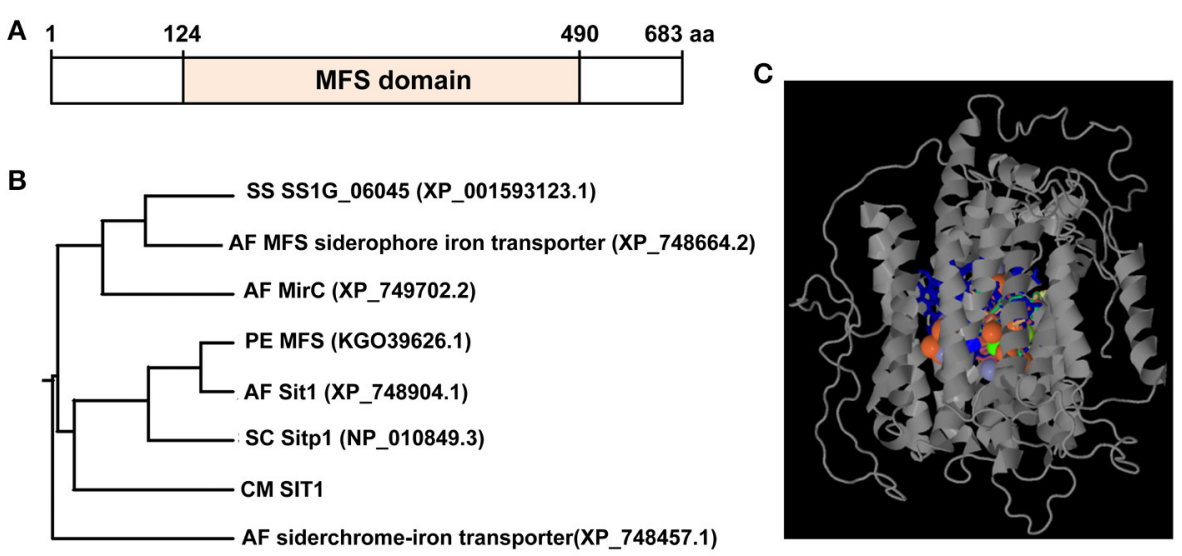

FIGURE 5 | C. minitans CmSIT1 has a conserved domain (aa124-aa490) of the major facilitator superfamily (MFS) transporter. (A) A diagram of CmSIT1 predicted with the Blastp program from the NCBI website; (B) A phylogenetic tree was constructed, using the MEGA5 program, based on reference siderophore transporter proteins from A. fumigatus, P. expansum, S. cerevisiae, and S. sclerotiorum. (C) The three dimensional (3D) model of CmSIT1 protein, which was generated with the Phyre2 program. The binding site was presented with colored amino acidic residues. 
TABLE 2 | The identities and positives between CmSIT1 of C. minitans and selected fungal homologs.

\begin{tabular}{|c|c|c|c|c|c|c|c|c|}
\hline Fungal namue & Gene name or function & Accession no. & Score & Expect & Identities & Positives & Gaps & References \\
\hline $\begin{array}{l}\text { Fonsecaea pedrosoi CBS } \\
271.37\end{array}$ & hypothetical protein Z517_06750 & XP_013283943.1 & $\begin{array}{l}298 \text { bits } \\
(764)\end{array}$ & $9 e-88$ & $\begin{array}{c}180 / 571 \\
(32 \%)\end{array}$ & $\begin{array}{c}303 / 571 \\
(53 \%)\end{array}$ & $\begin{array}{c}24 / 571 \\
(4 \%)\end{array}$ & $\begin{array}{l}\text { Cuomo et al., 2015, } \\
\text { unpublished }\end{array}$ \\
\hline Penicillium digitatum Pd1 & hypothetical protein PDIP_84890 & XP_014532645.1 & $\begin{array}{c}297 \text { bits } \\
\text { (761) }\end{array}$ & $2 \mathrm{e}-87$ & $\begin{array}{c}179 / 581 \\
(31 \%)\end{array}$ & $\begin{array}{c}316 / 581 \\
(54 \%)\end{array}$ & $\begin{array}{c}18 / 581 \\
(3 \%)\end{array}$ & $\begin{array}{l}\text { Marcet-Houben et al., } \\
2012\end{array}$ \\
\hline $\begin{array}{l}\text { Coccidioides immitis } \\
\text { RMSCC } 2394\end{array}$ & siderophore iron transporter 1 & KMP06227.1 & $\begin{array}{c}297 \text { bits } \\
\text { (760) }\end{array}$ & $4 e-87$ & $\begin{array}{c}174 / 562 \\
(31 \%)\end{array}$ & $\begin{array}{c}301 / 562 \\
(53 \%)\end{array}$ & $\begin{array}{c}18 / 562 \\
(3 \%)\end{array}$ & $\begin{array}{l}\text { Henn et al., } 2015 \\
\text { unpublished }\end{array}$ \\
\hline $\begin{array}{l}\text { Coniosporium apollinis CBS } \\
100218\end{array}$ & hypothetical protein W97_06828 & XP_007783002.1 & $\begin{array}{c}295 \text { bits } \\
\text { (754) }\end{array}$ & $2 e-86$ & $\begin{array}{c}172 / 556 \\
(31 \%)\end{array}$ & $\begin{array}{c}301 / 556 \\
(54 \%)\end{array}$ & $\begin{array}{c}10 / 556 \\
(1 \%)\end{array}$ & $\begin{array}{l}\text { Cuomo et al., 2014, } \\
\text { unpublished }\end{array}$ \\
\hline Coccidioides immitis RS & siderochrome-iron transporter Sit1 & XP_001240692.2 & $\begin{array}{l}294 \text { bits } \\
\text { (752) }\end{array}$ & $5 e-86$ & $\begin{array}{c}174 / 558 \\
(31 \%)\end{array}$ & $\begin{array}{c}301 / 558 \\
(53 \%)\end{array}$ & $\begin{array}{c}14 / 558 \\
(2 \%)\end{array}$ & $\begin{array}{l}\text { Neafsey et al., 2015, } \\
\text { unpublished }\end{array}$ \\
\hline $\begin{array}{l}\text { Coccidioides posadasii } \\
\text { C735 delta SOWgp }\end{array}$ & Major Facilitator Superfamily protein & XP_003067856.1 & $\begin{array}{c}293 \text { bits } \\
\text { (751) }\end{array}$ & $7 e-86$ & $\begin{array}{c}175 / 558 \\
(31 \%)\end{array}$ & $\begin{array}{c}301 / 558 \\
(53 \%)\end{array}$ & $\begin{array}{c}14 / 558 \\
(2 \%)\end{array}$ & Sharpton et al., 2009 \\
\hline $\begin{array}{l}\text { Colletotrichum orbiculare } \\
\text { MAFF } 240422\end{array}$ & siderophore iron transporter 1 & ENH80818.1 & $\begin{array}{c}293 \text { bits } \\
\text { (751) }\end{array}$ & $9 e-86$ & $\begin{array}{c}166 / 548 \\
(30 \%)\end{array}$ & $\begin{array}{c}292 / 548 \\
(53 \%)\end{array}$ & $\begin{array}{c}13 / 548 \\
(2 \%)\end{array}$ & $\begin{array}{l}\text { Gan et al., 2015, } \\
\text { unpublished }\end{array}$ \\
\hline $\begin{array}{l}\text { Emmonsia crescens UAMH } \\
3008\end{array}$ & $\begin{array}{l}\text { MFS transporter, SIT family, } \\
\text { siderophore-iron:H+ symporter }\end{array}$ & KKZ63768.1 & $\begin{array}{c}290 \text { bits } \\
(743)\end{array}$ & $8 e-85$ & $\begin{array}{c}169 / 553 \\
(31 \%)\end{array}$ & $\begin{array}{c}289 / 553 \\
(52 \%)\end{array}$ & $\begin{array}{c}24 / 553 \\
(4 \%\end{array}$ & $\begin{array}{l}\text { Cuomo et al., 2014, } \\
\text { unpublished }\end{array}$ \\
\hline Penicillium solitum & Major facilitator superfamily & KJJ23129.1 & $\begin{array}{c}289 \text { bits } \\
\text { (739) }\end{array}$ & $1 e-83$ & $\begin{array}{c}178 / 606 \\
(29 \%)\end{array}$ & $\begin{array}{c}321 / 606 \\
(52 \%)\end{array}$ & $\begin{array}{c}19 / 606 \\
(3 \%)\end{array}$ & $\begin{array}{l}\text { Yu et al., 2015, } \\
\text { unpublished }\end{array}$ \\
\hline $\begin{array}{l}\text { Penicillium rubens } \\
\text { Wisconsin 54-1255 }\end{array}$ & Pc13g04290 & XP_002558865.1 & $\begin{array}{c}287 \text { bits } \\
\text { (734) }\end{array}$ & $1 e-83$ & $\begin{array}{c}174 / 581 \\
(30 \%)\end{array}$ & $\begin{array}{c}316 / 581 \\
(54 \%)\end{array}$ & $\begin{array}{c}18 / 581 \\
(3 \%)\end{array}$ & $\begin{array}{l}\text { van den Berg et al., } \\
2008\end{array}$ \\
\hline Colletotrichum higginsianum & $\begin{array}{l}\text { major facilitator superfamily } \\
\text { transporter }\end{array}$ & CCF35502.1 & $\begin{array}{c}286 \text { bits } \\
\text { (733) }\end{array}$ & $3 e-83$ & $\begin{array}{c}183 / 598 \\
(31 \%)\end{array}$ & $\begin{array}{c}305 / 598 \\
(51 \%)\end{array}$ & $\begin{array}{c}36 / 598 \\
(6 \%)\end{array}$ & $\begin{array}{l}\text { Ma et al., } 2102 \text {, } \\
\text { unpublished }\end{array}$ \\
\hline Colletotrichum fioriniae PJ7 & $\begin{array}{l}\text { major facilitator superfamily } \\
\text { transporter }\end{array}$ & XP_007590024.1 & $\begin{array}{c}286 \text { bits } \\
\text { (733) }\end{array}$ & $4 e-83$ & $\begin{array}{c}178 / 617 \\
(29 \%)\end{array}$ & $\begin{array}{c}318 / 617 \\
(51 \%)\end{array}$ & $\begin{array}{c}31 / 617 \\
(5 \%)\end{array}$ & Baroncelli et al., 2014 \\
\hline
\end{tabular}

P. expansum, S. cerevisiae, and S. sclerotiorum (Figure 5C), and CmSIT1 was clustered with Sitp1 of S. cerevisiae, Sit1 of A. fumigates and MFS, a general substrate transporter of $P$. expansum. This further suggested that CmSIT1 is a SIT transporter.

\section{Overexpression of CmSIT1 Was Responsible for the Abnormal Phenotype of ZS-1TN1812}

The full length cDNA of CmSIT1 was cloned into the pCXH vector, transformed into A. tumefaciens EHA105, and then 
transformed into the wild-type strain ZS-1. The phenotypes, including growth rate, colony morphology, and production of antifungal substances, of the over-expression transformants were similar to that of ZS-1TN1812. The colony morphologies of over-expression transformants were shown in Figure 6A and the growth suppression of $S$. sclerotiorum was shown in Figure 6B. The CmSIT1 expression of overexpression transformants was also confirmed with RT-PCR (Figure 6C). Thus, the consistent expression of CmSIT1 could cause abnormal growth and excessive synthesis of antifungal substances.

\section{High Accumulation of Iron in ZS-1TN1812}

Iron homeostasis is very important for most organisms. We suspected that the abnormal phenotype of ZS-1TN1812 is likely to be caused by excess uptake of the iron element since CmSIT1 encodes a putative siderophore iron transporter. To test this hypothesis, both the wild-type and mutant strains were grown on PDA medium amended with different concentrations of ferric chloride and the results showed that the growth of the wildtype strain was inhibited when growing on $1 \mathrm{mM} \mathrm{FeCl}_{3}$-amended PDA medium. When the concentration of $\mathrm{FeCl}_{3}$ was increased, the inhibition was more significant, with wild-type strain growth almost completely inhibited when the concentration of $\mathrm{FeCl}_{3}$ in medium was $2.5 \mathrm{mM}$. The growth of ZS-1TN1812 in $2 \mathrm{mM} \mathrm{FeCl}$-amended PDA medium was not significantly different from that of non-amended PDA medium. However, complete inhibition of growth was observed when growing on $2.5 \mathrm{mM} \mathrm{FeCl}_{3}$-amended PDA medium. Interestingly, the colony morphology of the wild-type strain developed on $2 \mathrm{mM} \mathrm{FeCl}_{3}$ amended PDA medium was similar to that of ZS-1TN1812 on PDA medium (Figures 7A,B).

As an essential element, it is not surprising that iron could be detected in the hyphal mass of strains ZS-1 and ZS-1TN1812. However, the iron level in ZS-1TN1812 was significantly higher than in strain ZS-1 when growing on the PDA plate, with the iron concentration at $37.2 \mu \mathrm{M}$ in the mutant and only $16.3 \mu \mathrm{M}$ in the wild-type strain ZS-1. When growing on $2.0 \mathrm{mM}$ $\mathrm{FeCl}_{3}$-amended PDA, the iron levels in strain ZS-1 and strain ZS-1TN1812 were significantly higher, at 78.5 and $106.2 \mu \mathrm{M}$ (Figure 7C), respectively. This result combined with the results above suggested that iron-uptake ability in ZS-1TN1812 was significantly increased.

\section{CmSIT1 is Expressed When C. minitans Contacts Either Host or Non-host Fungi}

Although, the expression of CmSIT1 is not detectable via RT-PCR when growing on PDA medium alone, it may be expressed when dual-cultured with other microorganisms, since siderophores are important molecules in competition with other organisms for iron. To test this hypothesis, C. minitans was allowed to contact its host, S. sclerotiorum, or non-host, C. higginsianum, and the

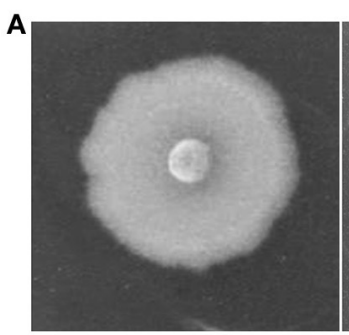

ZS-1TN1812

B

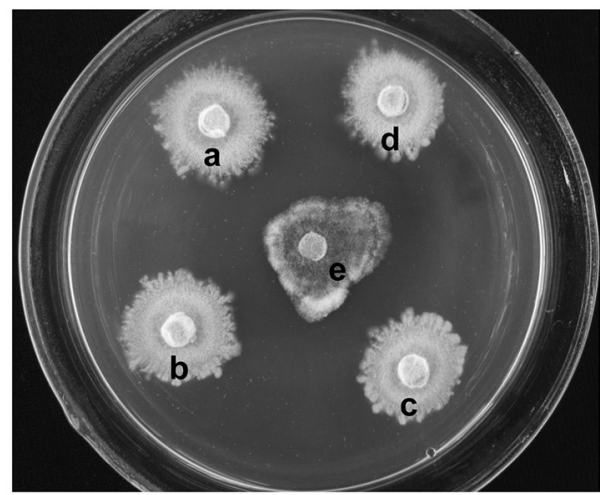

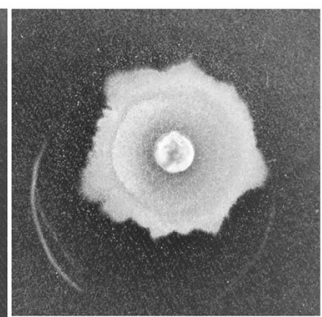

CmSIT1-OE2

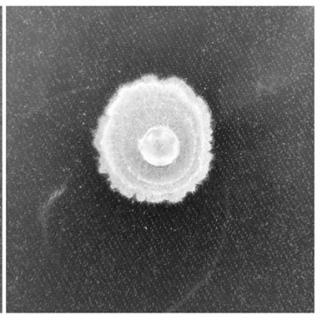

CmSIT1-OE3
C

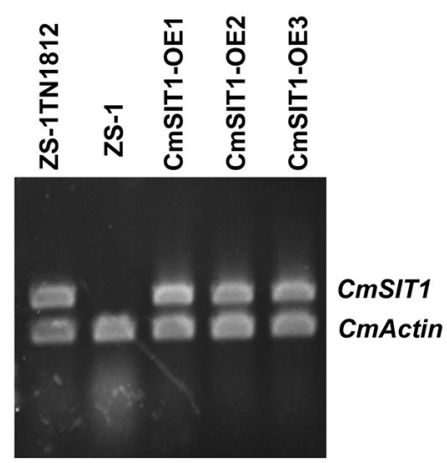

FIGURE 6 | The colony morphology of the CmSIT1-overexpression transformants of C. minitans. (A) Colony morphology of mutant ZS-1TN1812 and three over-expression transformants which cultured on PDA medium at $20^{\circ} \mathrm{C}$ for 10 days. (B) Transformants also have strong antagonistic ability, (a) ZS-1TN1812, (b) CmSIT1-OE1, (c) CmSIT1-OE2, (d) CmSIT1-OE3, and (e) Ep-1PNA367. S. sclerotiorum stain Ep-1PNA367 was inoculated after ZS-1TN1812 and transformants growing on PDA for 4 days. Then all the strains were co-cultured for 7 days at $20^{\circ} \mathrm{C}$. (C) RT-PCR analysis the expression of CmSIT1 gene in CmSIT1-overexpression transformants. Strains were cultured on PDA medium for $48,72,96$, or $120 \mathrm{~h}$, and then the mycelia were mixed together equally to extract the total RNA. 


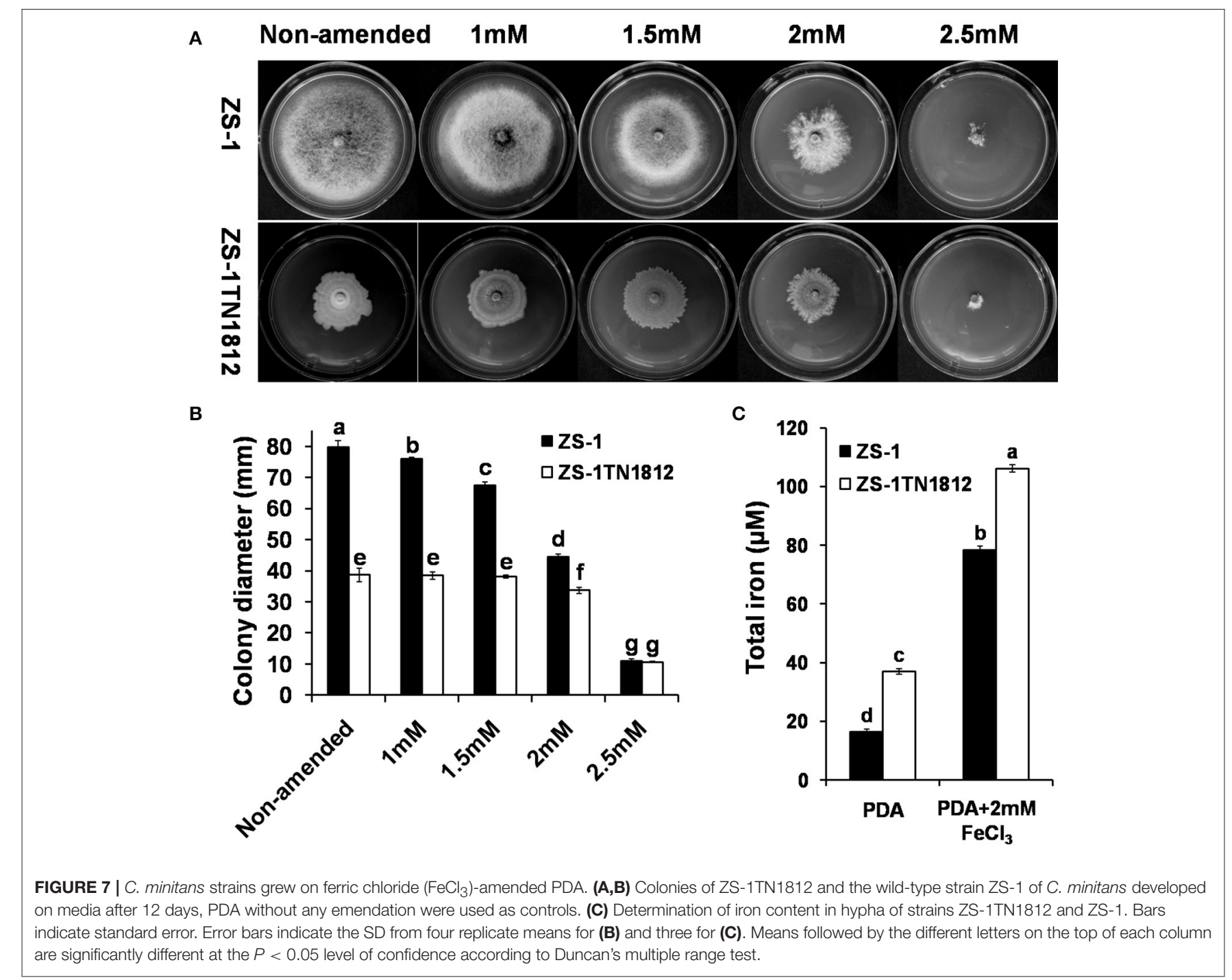

expression of CmSIT1 was determined using qRT-PCR. The results showed that when contacting $S$. sclerotiorum, CmSIT1 was significantly expressed at 2 days post-inoculation (dpi), and the expression declined at 4 and $5 \mathrm{dpi}$, but the expression level was still significantly higher than when growing on PDA alone. When C. minitans and non-host C. higginsianum grew on PDA, CmSIT1 was highly expressed at $2 \mathrm{dpi}$ and the high level of expression was maintained even at $4 \mathrm{dpi}$, but dropped significantly at $5 \mathrm{dpi}$ (Figure 8). This result suggested that CmSIT1 may play a role during parasitizing, such as competing for iron with its host, S. sclerotiorum.

\section{DISCUSSION}

Our research identified a siderophore iron transporter gene CmSIT1 from the sclerotial parasite C. minitans. CmSIT1 has 683 amino acid residues with a conserved domain (amino acid 124-490) of the MFS transporter. CmSIT1 is relatively large compared to all other fungal SIT1 homologs. Some other large SIT proteins are the MFS transporter (KJJ23129.1) of Penicillium solitum, with 651 aa, and a hysipothetical protein CPAR2-803030 (CCE41752.1) of Candida parapsilosis, with 648 aa, and a putative siderophore iron transporter, mirb (GAP91069.1), from Rosellinia necatrix, with 647 aa. An annotated hypothetical protein (XP_001593123.1) and homolog of CmSIT1 was identified from S. sclerotiorum, the host of C. minitans. The expression of CmSIT1 was not detected by RTPCR when growing on PDA medium, while it could be detected when dual-cultured with its host. Overexpression of CmSIT1 in C. minitans led to extremely slow growth on PDA medium and development of an abnormal colony morphology. Importantly, it could produce large levels of antifungal substances to antagonize the growth of $S$. sclerotiorum, and when sprayed on leaves of rapeseed, it could inhibit the lesion formation induced by S. sclerotiorum.

C. minitans produces AFS, specifically suppressing S. sclerotiorum. McQuilken et al. (2002) found that C. minitans could produce antifungal metabolites and the production of these 


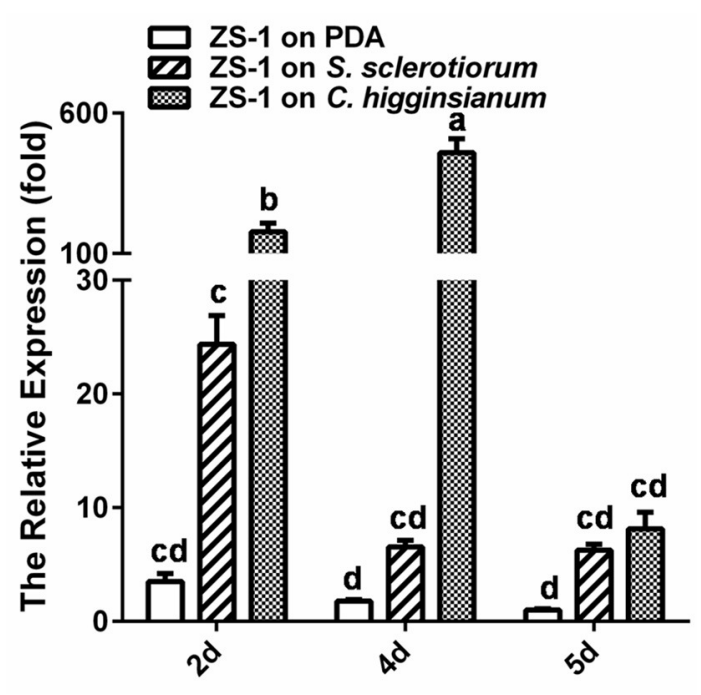

FIGURE 8 | Inducible expression of CMSIT1 in C. miniatns when contacting with its host, S. sclerotiorum and non-host fungus, C. higginsianum 2, 4, and 5 dpi. The relative levels of transcript were calculated by the comparative Ct method. The levels of actin transcript were used to normalize different samples. The relative expression level of CmSIT1 in the wide-type stain ZS-1 for $5 \mathrm{~d}$ was assigned as value 1. Bars represent means and standard deviations (three replications). Error bars indicate the SD from four replicate means. Means followed by the different letters on the top of each column are significantly different at the $P<0.05$ level of confidence according to Duncan's multiple range test.

could be affected by nutritional factors. After that, they identified four closely related metabolites from filtrates of $C$. minitans, one of which was macrosphelide A. Macrosphelide A had a wide antagonistic spectrum (McQuilken et al., 2003; Tomprefa et al., 2009). Yang et al. (2007) reported that the filtrate of C. minitans had antifungal activity and could suppress the germination of S. sclerotiorum ascospores and inhibit the expansion of lesions induced by $S$. sclerotiorum on rapeseed leaves, and there was a possibility that the antifungal activity in the filtrate may partially contribute to the fungal-cell wall enzymes of $C$. minitans. Yang et al. (2008) found that both ambient $\mathrm{pH}$ and nutritional factors affected the antifungal activity of the mycoparasite $C$. minitans and this finding led to the recent discovery that $\mathrm{CmpacC}$ regulates mycoparasitism, oxalate degradation, and antifungal activity of C. minitans (Zeng et al., 2014; Lou et al., 2015). Interestingly, the $\mathrm{PacC}$-mediated ambient-pH regulatory system in $A$. nidulans was found to regulate the biosynthesis and uptake of siderophores (Eisendle et al., 2004). Our findings suggested that $C$. minitans could produce antifungal substances specifically inhibiting the growth of S. sclerotiorum and that CmSIT1 was involved in the production of these antifungal substances. In the wild-type strain, CmSIT1 was only highly expressed at the early stages of contact with its host, S. sclerotiorum. This finding suggested that the antifungal substances may transiently function at the early stages of the interaction between C. minitans and S. sclerotiorum. C. minitans could regulate the balance between production of antifungal substances and mycoparasitism, since
C. minitans is not capable of completely suppressing its host's growth on rapeseed, as was our original expectation.

Our study suggested that $C$. minitans had the potential to produce several kinds of antagonistic substances. In ZS-1TN1812, the antifungal substances could be classified into two groups based on thermo-tolerance, namely non-thermotolerant antifungal substances, and thermo-tolerant antifungal substances. Because the thermo-tolerant antifungal substances could specifically suppress the growth of S. sclerotiorum, this antifungal substance was not likely to be macrosphelide A, which has a wide antagonistic spectrum. Of striking contrast with the wild-type strain, spraying the filtrate of ZS-1TN1812 on the leaves of rapeseed could highly inhibit the infection and lesion formation of $S$. sclerotiorum, suggesting that the antifungal substances produced by this mutant could be effective on the leaves. Further investigation into the substances produced by ZS-1TN1812, such as isolation, identification, and characterization, may lead to the discovery of new chemicals against plant diseases caused by $S$. sclerotiorum.

Indeed, C. minitans has to overcome competition and threat from microorganisms other than parasitizing S. sclerotiorum. We found that ZS-1TN1812 could produce a proteinous antifungal substances that could significantly inhibit the growth of C. higginsianum, and found that the expression of CmSIT1 in the wild-type strain of $C$. minitans could be stimulated when growing on PDA with $C$. higginsianum, suggesting that C. minitans could explore the siderophore transporter system by taking in iron from ambient environments, and this may lead to competition with other organisms for iron and stimulate the synthesis of aproteinous antifungal substances that work against other fungi. Thus, CmSIT1 is likely to play an important ecological role for C. minitans, allowing it to survive in nature.

In Acremonium chrysogenum, a producer of the betalactam antibiotic cephalosporin $\mathrm{C}$, starvation could induce the production of the extracellular siderophores and the expression of a putative siderophore transporter gene, mir1 (Gsaller et al., 2012). We currently have not investigated if $C$. minitans produces siderophores or if these siderophores could be synthesized and secreted under CmSIT1 expression. However, we found that the colony morphology of the wild-type strain, when grown on $2 \mathrm{mM} \mathrm{FeCl}_{3}$-amending PDA medium, was similar to that of ZS-1TN1812, suggesting the abnormal phenotype of ZS-1TN1812 was possibly due to high iron accumulation of in fungal cells. This hypothesis was confirmed by the detection of iron in mycelium of strain ZS-1TN1812 and ZS-1 when growing on PDA and $2 \mathrm{mM} \mathrm{FeCl}_{3}$-amended PDA medium.

Siderophores are considered one of the mechanisms through which some beneficial microorganisms antagonize plant pathogens (Berendsen et al., 2015). Fungi may produce several kinds of siderophores, with the exception of S. cerevisiae, which does not synthesize any siderophore, and siderophore-iron transporters may only specifically bind and transport certain types of siderophores. Although only one putative siderophore iron transporter, SS1G_06045 (XP_001593123.1), could be found with the Sitp1 of S. cerevisiae as the seed sequence, SS1G_06045 is phylogenetically distant from CmSIT1, suggesting that C. minitans and its host, S. sclerortiorum, may use different 
siderophores to bind iron and C. minitans may weaken the resistance of $S$. sclerotiorum to establish mycoparasitism at the early stages of infection.

CmSIT1 is a potential gene for improving the control ability of C. minitans. Although, C. minitans could produce antifungal substances, the amount of antifungal substances produced by the wild-type strain is not enough to suppress the growth of S. sclerotiorum. Usually a no-inhibition zone could be observed when dual-culturing on PDA medium and C. minitans could not efficiently suppress the lesion expansion induced by $S$. sclerotiorum on rapeseed leaves. This is disadvantageous and limits the widespread use of $C$. minitans, leading to difficulty in aerial parts control, which contributes to Sclerotinia disease. In our study, we found that the antifungal substances produced by ZS-1TN1812 were likely to contain two types of active compounds, namely, non-proteinous antibiotics, and proteinous antibiotics. $S$. sclerotiorum showed more tolerant to the proteinous antibiotics produced by the mutant and was specifically sensitive to the non-proteinous antifungal substances, while another fungus, $C$. higginsianum, was sensitive to the proteinous antibiotics. Overexpression of $C m S I T 1$ proved to be a double-edged sword, as it improved the production of antifungal substances, while it also restricted the growth, conidiation, and parasitization of C. minitans. Tightly controlled expression of CmSIT1 through genetic modification may strengthen the

\section{REFERENCES}

Ballester, A. R., Marcet-Houben, M., Levin, E., Sela, N., Selma-Lázaro, C., Carmona, L., et al. (2015). Genome, transcriptome, and functional analyses of penicillium expansum provide new insights into secondary metabolism and pathogenicity. Mol. Plant Microbe Interact. 28, 232-248. doi: 10.1094/MPMI-09-14-0261-FI

Baroncelli, R., Sreenivasaprasad, S., Sukno, S. A., Thon, M. R., and Holub, E. (2014). Draft genome sequence of Colletotrichum acutatum sensu lato (Colletotrichum fioriniae). Genome Announc. 2, e00112-e00114. doi: 10.1128/genomeA.00112-14

Bennett, A. J., Leifert, C., and Whipps, J. M. (2006). Survival of Coniothyrium minitans associated with sclerotia of Sclerotinia sclerotiorum in soil. Soil Biol. Biochem. 38, 164-172. doi: 10.1016/j.soilbio.2005.04.032

Berendsen, R. L., van Verk, M. C., Stringlis, I. A., Zamioudis, C., Tommassen, J., Pieterse, C. M., et al. (2015). Unearthing the genomes of plant-beneficial Pseudomonas model strains WCS358, WCS374 and WCS417. BMC Genomics 16, 539. doi: 10.1186/s12864-015-1632-z

Budge, S. P., and Whipps, J. M. (2001). Potential for integrated control of Sclerotinia sclerotiorum in glasshouse lettuce using Coniothyrium minitans and reduced fungicide application. Phytopathology 91, 221-227. doi: 10.1094/PHYTO.2001.91.2.221

Chen, L. H., Lin, C. H., and Chung, K. R. (2013). A nonribosomal peptide synthetase mediates siderophore production and virulence in the citrus fungal pathogen Alternaria alternate. Mol. Plant Pathol. 14, 497-505. doi: $10.1111 / \mathrm{mpp} .12021$

Cheng, J., Jiang, D., Yi, X., Fu, Y., Li, G., and Whipps, J. (2003). Production, survival and efficacy of Coniothyrium minitans conidia produced in shaken liquid culture. FEMS Microbiol. Lett. 227, 127-131. doi: 10.1016/S0378-1097(03)00666-9

Cheeseman, K., Ropars, J., Renault, P., Dupont, J., Gouzy, J., Branca, A., et al. (2014). Multiple recent horizontal transfers of a large genomic region in cheese making fungi. Nat Commun 5, 2876. doi: 10.1038/ncomms3876

Condon, B. J., Oide, S., Gibson, D. M., Krasnoff, S. B., and Turgeon, B. G. (2014). Reductive iron assimilation and intracellular siderophores assist antagonistic ability of C. minitans during interaction with S. sclerotiorum.

\section{CONCLUSION}

In this research, CmSIT1, a gene involved in siderophoremediated iron transport, was cloned and the functions were studied in C. minitans, a mycoparasite of $S$. sclerotiorum. Expression of CmSIT1 led to reduced growth and enhanced antifungal ability. The antifungal substances could significantly inhibit the infection of S. sclerotiorum on the leaves of rapeseed.

\section{AUTHOR CONTRIBUTIONS}

$\mathrm{XS}, \mathrm{DJ}$, and YF designed the research and wrote the paper; XS, YZ, JJ, JX, and JC executed the experiments. JC, JX, YZ, HL, and YF performed the data and bioinformatics analyses. All authors read and approved the final manuscript.

\section{ACKNOWLEDGMENTS}

This research was supported by the National Key R\&D Program of China (2017YFD0200400), the National Natural Science Foundation of China (Grant 31572048), and the earmarked fund for China Agriculture Research System (CARS-13). extracellular siderophore-driven iron homeostasis and virulence. Mol. Plant Microbe Interact. 27, 793-808. doi: 10.1094/MPMI-11-13-0328-R

Diamantopoulou, A., Litkei, J., and Skopa, C. (2000). Effects of inhibitors of sclerotium formation on the sclerotial mycoparasite Coniothyrium minitans and its host Sclerotinia sclerotiorum. Mycol. Res. 104, 1449-1452. doi: 10.1017/S0953756200002884

Ding, C., Festa, R. A., Sun, T. S., and Wang, Z. Y. (2014). Iron and copper as virulence modulators in human fungal pathogens. Mol. Microbiol. 93, 10-23. doi: $10.1111 / \mathrm{mmi} .12653$

Giuliano Garisto Donzelli, B., Gibson, D. M., and Krasnoff, S. B. (2015) Intracellular siderophore but not extracellular siderophore is required for full virulence in Metarhizium robertsii. Fungal Genet. Biol. 82, 56-68. doi: 10.1016/j.fgb.2015.06.008

Eisendle, M., Oberegger, H., Buttinger, R., Illmer, P., and Haas, H. (2004). Biosynthesis and uptake of siderophores is controlled by the PacC-mediated ambient-pH regulatory system in Aspergillus nidulans. Eukaryot. Cell 3, 561-563. doi: 10.1128/EC.3.2.561-563.2004

Eisendle, M., Schrettl, M., Kragl, C., Müller, D., Illmer, P., and Haas, H. (2006). The intracellular siderophore ferricrocin is involved in iron storage, oxidativestress resistance, germination, and sexual development in Aspergillus nidulans. Eukaryot. Cell 5, 1596-1603. doi: 10.1128/EC.00057-06

Gerlagh, M., Goossen-van de Geijn, H. M., Fokkema, N. J., and Vereijken, P. F. (1999). Long-term biosanitation by application of Coniothyrium minitans on Sclerotinia sclerotiorum-infected crops. Phytopathology 89, 141-147. doi: 10.1094/PHYTO.1999.89.2.141

Gong, X., Fu, Y., Jiang, D., Li, G., Yi, X., and Peng, Y. (2007). L-arginine is essential for conidiation in the filamentous fungus Coniothyrium minitans. Fungal Genet. Biol. 44, 1368-1379. doi: 10.1016/j.fgb.2007.07.007

Gsaller, F., Blatzer, M., Abt, B., Schrettl, M., Lindner, H., and Haas, H. (2012). The first promoter for conditional gene expression in Acremonium chrysogenum: iron starvation-inducible mir1P. J. Biotechnol. 163, 77-80. doi: 10.1016/j.jbiotec.2012.10.008

Haas, H. (2014). Fungal siderophore metabolism with a focus on Aspergillus fumigatus. Nat. Prod. Rep. 31, 1266-1276. doi: 10.1039/C4NP0 $0071 \mathrm{D}$ 
Haas, H., Eisendle, M., and Turgeon, B. G. (2008). Siderophores in fungal physiology and virulence. Annu. Rev. Phytopathol. 46, 149-187. doi: 10.1146/annurev.phyto.45.062806.094338

Heng, J., Zhao, Y., Liu, M., Liu, Y., Fan, J., Wang, X., et al. (2015). Substrate-bound structure of the E. coli multidrug resistance transporter MdfA. Cell Res. 25, 1060-1073. doi: 10.1038/cr.2015.94

Heymann, P., Gerads, M., Schaller, M., Dromer, F., Winkelmann, G., and Ernst, J. F. (2002). The siderophore iron transporter of Candida albicans (Sit1p/Arn1p) mediates uptake of ferrichrome-type siderophores and is required for epithelial invasion. Infect. Immun. 70, 5246-5255. doi: 10.1128/IAI.70.9.5246-5255.2002

Hissen, A. H., Wan, A. N., Warwas, M. L., Pinto, L. J., and Moore, M. M. (2005). The Aspergillus fumigates siderophore biosynthetic gene sidA, encoding L-ornithine N5-oxygenase, is required for virulence. Infect. Immun. 73, 5493-5503. doi: 10.1128/IAI.73.9.5493-5503.2005

Jin, H., Hartman, G. L., Nickell, C. D., and Widholm, J. M. (1996). Characterization and purification of a phytotoxin produced by Fusarium solani, the causal agent of soybean sudden death syndrome. Phytopathology 86, 277-282. doi: 10.1094/Phyto-86-277

Jones, E. E., Mead, A., and Whipps, J. M. (2004). Effect of inoculum type and timing of application of Coniothyrium minitans on Sclerotinia sclerotiorum: control of sclerotinia disease in glasshouse lettuce. Plant Pathol. 53, 611-620. doi: 10.1111/j.1365-3059.2004.01071.x

Jones, E. E., and Whipps, J. M. (2002). Effect of inoculum rates and sources of Coniothyrium minitans on control of Sclerotinia sclerotiorum disease in glasshouse lettuce. Eur. J. Plant Pathol. 108, 527-538. doi: 10.1023/A:1019940820230

Källberg, M., Wang, H., Wang, S., Peng, J., Wang, Z., Lu, H., et al. (2012). Template-based protein structure modeling using the RaptorX web server. Nat. Protoc. 7, 1511-1522. doi: 10.1038/nprot.2012.085

Kaplan, J., McVey Ward, D., Crisp, R. J., and Philpott, C. C. (2006). Iron-dependent metabolic remodeling in S. cerevisiae. Biochim. Biophys. Acta. 1763, 646-651. doi: 10.1016/j.bbamcr.2006.03.008

Kelley, L. A., Mezulis, S., Yates, C. M., Wass, M. N., and Sternberg, M. J. E. (2015). The Phyre 2 web portal for protein modeling, prediction and analysis. Nat. Protoc. 10, 845-858. doi: 10.1038/nprot.2015.053

Kelley, L. A., and Sternberg, M. J. (2009). Protein structure prediction on the Web: a case study using the Phyre server. Nat. Protoc. 4, 363-371. doi: $10.1038 /$ nprot.2009.2

Kosman, D. J. (2003). Molecular mechanisms of iron uptake in fungi. Mol. Microbiol. 47, 1185-1197. doi: 10.1046/j.1365-2958.2003.03368.x

Labbé, S., Pelletier, B., and Mercier, A. (2007). Iron homeostasis in the fission yeast Schizosaccharomyces pombe. Biometals 20, 523-537. doi: 10.1007/s10534-006-9056-5

Larkin, M. A., Blackshields, G., Brown, N. P., Chenna, R., McGettigan, P. A., McWilliam, H., et al. (2007). Clustal, W., and Clustal X version 2.0. Bioinformatics 23, 2947-2948. doi: 10.1093/bioinformatics/btm404

Li, G. Q., Huang, H. C., Miao, H. J., Erickson, R. S., Jiang, D. H., and Xiao, Y. N. (2006). Biological control of Sclerotinia diseases of rapeseed by aerial applications of the mycoparasite Coniothyrium minitans. Eur. J. Plant Pathol. 114, 345-355. doi: 10.1007/s10658-005-2232-6

Li, M., Gong, X., Zheng, J., Jiang, D., Fu, Y, and Hou, M. (2005). Transformation of Coniothyrium minitans, a parasite of Sclerotinia sclerotiorum, with Agrobacterium tumefaciens. FEMS Microbiol. Lett. 243, 323-329. doi: 10.1016/j.femsle.2004.12.033

Lou, Y., Han, Y., Yang, L., Wu, M., Zhang, J., Cheng, J., et al. (2015). CmpacC regulates mycoparasitism, oxalate degradation and antifungal activity in the mycoparasitic fungus Coniothyrium minitans. Environ. Microbiol. 17, 4711-4729. doi: 10.1111/1462-2920.13018

Marcet-Houben, M., Ballester, A.-R., de la Fuente, B., Harries, E., Marcos, J. F., González-Candelas, L., et al. (2012). Genome sequence of the necrotrophic fungus Penicillium digitatum, the main postharvest pathogen of citrus. BMC Genomics 13:646. doi: 10.1186/1471-2164-13-646

McQuilken, M. P., and Chalton, D. (2009). Potential for biocontrol of sclerotinia rot of carrot with foliar sprays of Contans WG (Coniothyrium minitans). Biocontrol Sci. Technol. 19, 229-235. doi: 10.1080/09583150802635549

McQuilken, M. P., Gemmell, J., Hill, R. A., and Whipps, J. M. (2003). Production of macrosphelide A by the mycoparasite Coniothyrium minitans. FEMS Microbiol. Lett. 219, 27-31. doi: 10.1016/S0378-1097(02)01180-1
McQuilken, M. P., Gemmell, J., and Whipps, J. M. (2002). Some nutritional factors affecting production of biomass and antifungal metabolites of Coniothyrium minitans. Biocontrol Sci. Technol. 12, 443-454. doi: 10.1080/09583150220146022

Mei, B., Budde, A. D., and Leong, S. A. (1993). sid1, a gene initiating siderophore biosynthesis in Ustilago maydis: molecular characterization, regulation by iron, and role in phytopathogenicity. Proc. Natl. Acad. Sci. U.S.A. 90, 903-907. doi: 10.1073/pnas.90.3.903

Meng, Y., Patel, G., Heist, M., Betts, M. F., Tucker, S. L., Galadima, N., et al. (2007). A systematic analysis of T-DNA insertion events in Magnaporthe oryzae. Fungal Genet. Biol. 44, 1050-1064. doi: 10.1016/j.fgb.2007.04.002

Moore, M. M. (2013). The crucial role of iron uptake in Aspergillus fumigatus virulence. Curr. Opin. Microbiol. 16, 692-699. doi: 10.1016/j.mib.2013. 07.012

Nevitt, T., and Thiele, D. J. (2011). Host iron withholding demands siderophore utilization for Candida glabrata to survive macrophage killing. PLoS Pathog. 7:1001322. doi: 10.1371/journal.ppat.1001322

Oide, S., Moeder, W., Krasnoff, S., Gibson, D., Haas, H., Yoshioka, K., et al. (2006). NPS6, encoding a nonribosomal peptide synthetase involved in siderophoremediated iron metabolism, is a conserved virulence determinant of plant pathogenic ascomycetes. Plant Cell 18, 2836-2853. doi: 10.1105/tpc.106. 045633

Partridge, D. E., Sutton, T. B., Jordan, D. L., and Bailey, J. E. (2006). Management of Sclerotinia blight of peanut with the biological control agent Coniothyrium minitans. Plant Dis. 90, 957-963. doi: 10.1094/PD-90-0957

Qin, L., Gong, X., Xie, J., Jiang, D., Cheng, J., Li, G., et al. (2011). Phosphoribosylamidotransferase, the first enzyme for purine de novo synthesis, is required for conidiation in the sclerotial mycoparasite Coniothyrium minitans. Fungal Genet. Biol. 48, 956-965. doi: 10.1016/j.fgb.2011. 06.007

Sambrook, J., and Russell, D. W. (2001). Molecular Cloning: A Laboratory Manual. Cold Spring Harbor, NY: Cold Spring Harbor Laboratory Press.

Schrettl, M., Bignell, E., Kragl, C., Joechl, C., Rogers, T., Arst, H. N. Jr., et al. (2004). Siderophore biosynthesis but not reductive iron assimilation is essential for Aspergillus fumigatus virulence. J. Exp. Med. 200, 1213-1219. doi: 10.1084 /jem. 20041242

Schwartze, V. U., Winter, S., Shelest, E., Marcet-Houben, M., Horn, F., Wehner, S., et al. (2014). Gene expansion shapes genome architecture in the human pathogen Lichtheimia corymbifera: an evolutionary genomics analysis in the ancient terrestrial Mucorales (Mucoromycotina). PLoS Genet. 10:1004496. doi: 10.1371/journal.pgen.1004496

Seifert, M., Nairz, M., Schroll, A., Schrettl, M., Haas, H., and Weiss, G. (2008). Effects of the Aspergillus fumigates siderophore systems on the regulation of macrophage immune effector pathways and iron homeostasis. Immunology 213, 767-778. doi: 10.1016/j.imbio.2008.07.010

Sharpton, T. J., Stajich, J. E., Rounsley, S. D., Gardner, M. J., Wortman, J. R., Jordar, V. S., et al. (2009). Comparative genomic analyses of the human fungal pathogens Coccidioides and their relatives. Genome Res. 19, 1722-1731. doi: 10.1101/gr.087551.108

Tomprefa, N., Hill, R., Whipps, J. M., and McQuilken, M. (2011). Some environmental factors affect growth and antibiotic production by the mycoparasite Coniothyrium minitans. Biocontrol Sci. Technol. 21, 721-731. doi: 10.1080/09583157.2011.575211

Tomprefa, N., McQuilken, M. P., Hill, R. A., and Whipps, J. M. (2009). Antimicrobial activity of Coniothyrium minitans and its macrolide antibiotic macrosphelide A. J. Appl. Microbiol. 106, 2048-2056. doi: 10.1111/j.1365-2672.2009.04174.x

van den Berg, M. A., Albang, R., Albermann, K., Badger, J. H., Daran, J. M., Driessen, A. J., et al. (2008). Genome sequencing and analysis of the filamentous fungus Penicillium chrysogenum. Nat. Biotechnol. 26, 1161-1168. doi: $10.1038 /$ nbt.1498

Van der Helm, D., and Winkelmann, G. (1994). "Hydroxamates and polycarboxylates as iron transport agents (siderophores) in fungi," in Metal, Ions in Fungi, eds G. Winkelmann, D. R. Winge (New York, NY: Marcel Dekker), 39-98.

Whipps, J. M., and Gerlagh, M. (1992). Biology of Coniothyrium minitans and its potential for use in disease biocontrol. Mycol. Res. 96, 897-907. doi: 10.1016/S0953-7562(09)80588-1 
Whipps, J. M., Sreenivasaprasad, S., Muthumeenakshi, S., Rogers, C. W., and Challen, M. P. (2008). Use of Coniothyrium minitans as a biocontrol agent and some molecular aspects of sclerotial mycoparasitism. Eur. J. Plant Pathol. 121, 323-330. doi: 10.1007/s10658-007-9238-1

Winkelmann, G. (2007). Ecology of siderophores with special reference to the fungi. Biometals 20, 379-392. doi: 10.1007/s10534-006-9076-1

Xie, J., Wei, D., Jiang, D., Fu, Y., Li, G., Ghabrial, S., et al. (2006). Characterization of debilitation-associated mycovirus infecting the plant-pathogenic fungus Sclerotinia sclerotiorum. J. Gen. Virol. 87, 241-249. doi: 10.1099/vir.0.81 $522-0$

Yang, R., Han, Y. C., Li, Q., Jiang, D. H., and Huang, H. C. (2007). Suppression of Sclerotinia sclerotiorum by antifungal substances produced by the mycoparasite Coniothyrium minitans. Eur. J. Plant Pathol. 119, 411-420. doi: 10.1007/s10658-007-9174-0

Yang, R., Han, Y. C., Li, Q., Jiang, D. H., and Huang, H. C. (2008). Effects of ambient $\mathrm{pH}$ and nutritional factors on antifungal activity of the mycoparasite Coniothyrium minitans. Biol. Control 44, 116-127. doi: 10.1016/j.biocontrol.2007.08.008
Zeng, L. M., Zhang, J., Han, Y. C., Yang, L., Wu, M. D., Jiang, D. H., et al. (2014). Degradation of oxalic acid by the mycoparasite Coniothyrium minitans plays an important role in interacting with Sclerotinia sclerotiorum. Environ. Microbiol. 16, 2591-2610. doi: 10.1111/1462-2920.12409

Conflict of Interest Statement: The authors declare that the research was conducted in the absence of any commercial or financial relationships that could be construed as a potential conflict of interest.

The reviewer JM-A and handling Editor declared their shared affiliation.

Copyright (c) 2017 Sun, Zhao, Jia, Xie, Cheng, Liu, Jiang and Fu. This is an openaccess article distributed under the terms of the Creative Commons Attribution License (CC BY). The use, distribution or reproduction in other forums is permitted, provided the original author(s) or licensor are credited and that the original publication in this journal is cited, in accordance with accepted academic practice. No use, distribution or reproduction is permitted which does not comply with these terms. 